\title{
Habitat-induced degradation of sound signals: Quantifying the effects of communication sounds and bird location on blur ratio, excess attenuation, and signal- to-noise ratio in blackbird song
}

\author{
Dabelsteen, T.; Larsen, O N; Pedersen, Simon Boel
}

Published in:

Acoustical Society of America. Journal

Link to article, DOI:

$10.1121 / 1.406682$

Publication date:

1993

Document Version

Publisher's PDF, also known as Version of record

Link back to DTU Orbit

Citation (APA):

Dabelsteen, T., Larsen, O. N., \& Pedersen, S. B. (1993). Habitat-induced degradation of sound signals:

Quantifying the effects of communication sounds and bird location on blur ratio, excess attenuation, and signalto-noise ratio in blackbird song. Acoustical Society of America. Journal, 93(4), 2206-2220.

https://doi.org/10.1121/1.406682

\section{General rights}

Copyright and moral rights for the publications made accessible in the public portal are retained by the authors and/or other copyright owners and it is a condition of accessing publications that users recognise and abide by the legal requirements associated with these rights.

- Users may download and print one copy of any publication from the public portal for the purpose of private study or research.

- You may not further distribute the material or use it for any profit-making activity or commercial gain

- You may freely distribute the URL identifying the publication in the public portal 


\title{
Habitat-induced degradation of sound signals: Quantifying the effects of communication sounds and bird location on blur ratio, excess attenuation, and signal-to-noise ratio in blackbird song
}

\author{
Torben Dabelsteen \\ Institute of Population Biology, University of Copenhagen, Universitetsparken 15, DK-2100 Copenhagen ø, \\ Denmark \\ Ole Næsbye Larsen \\ Institute of Biology, Odense University, Campusvej 55, DK-5230 Odense M, Denmark \\ Simon Boel Pedersen \\ Electronics Institute, Technical University, DK-2800 Lyngby, Denmark
}

(Received 21 April 1992; accepted for publication 1 December 1992)

\begin{abstract}
The habitat-induced degradation of the full song of the blackbird (Turdus merula) was quantified by measuring excess attenuation, reduction of the signal-to-noise ratio, and blur ratio, the latter measure representing the degree of blurring of amplitude and frequency patterns over time. All three measures were calculated from changes of the amplitude functions (i.e., envelopes) of the degraded songs using a new technique which allowed a compensation for the contribution of the background noise to the amplitude values. Representative songs were broadcast in a deciduous forest without leaves and rerecorded. Speakers and microphones were placed at typical blackbird emitter and receiver positions. Analyses showed that the three degradation measures were mutually correlated, and that they varied with $\log$ distance. Their variation suggests that the broadcast song could be detected across more than four, and discriminated across more than two territories. The song's high-pitched twitter sounds were degraded more rapidly than its lowpitched motif sounds. Motif sounds with a constant frequency projected best. The effect of microphone height was pronounced, especially on motif sounds, whereas the effect of speaker height was negligible. Degradation was inversely proportional to microphone height. Changing the reception site from a low to a high position reduced the degradation by the same amount as by approaching the sound source across one-half or one-whole territory. This suggests that the main reason for a male to sing from a high perch is to improve the singer's ability to hear responses to its songs, rather than to maximize the transmission distance. The difference in degradation between low and high microphone heights may explain why females, which tend to perch on low brush, disregard certain degradable components of the song.
\end{abstract}

PACS numbers: 43.80.Lb, 43.80.Ev

\section{INTRODUCTION}

Sound signals are degraded to some extent as they propagate through a natural habitat. Consequently, the detectability, locatability, and readability of bird song is reduced with distance. In physical terms, degradation typically has three aspects: blurring of amplitude and frequency patterns induced by selective frequency filtering, reverberation, and atmospheric turbulence (e.g., Wiley and Richards, 1982; Michelsen and Larsen, 1983); attenuation produced by absorption, multiple scattering, and geometric attenuation (e.g., Michelsen, 1978); and reduced signal-tonoise ratio $(\mathrm{S} / \mathrm{N})$. The information content of bird song therefore depends on the sound's resistance to these three aspects of degradation and its ability to reach the intended receivers with a sufficiently intact set of information carrying parameters.

Different aspects of sound degradation and adaptation for acoustic communication have been studied, but no study has yet included all three aspects of degradation. Most studies have determined the attenuation of pure tones and/or white noise broadcast at different heights above ground and at different distances in various habitats. These studies concentrate on the correspondence between the frequency content of animal vocalizations and the frequency filtering properties of the habitat in which they are used (e.g., Chappuis, 1971; Morton, 1975; Marten and Marler, 1977; Marten et al., 1977; Cosens and Falls, 1984; Waser and Brown, 1984; Price, 1988; Waide and Narins, 1988). A few studies have measured excess attenuation as well as $\mathrm{S} / \mathrm{N}$ of natural sounds in order to quantify the distance from the source over which the song amplitude remains above detection threshold of receivers, e.g., Brenowitz (1982). The majority of these studies have used SPL meters and/or graphic level recorders to determine the amplitude values. Since both the test sound and the background noise may have contributed to these results, the degree of attenuation of the test sounds may have been 
underestimated. Still other studies quantified the degree of blurring of artificial and natural sounds (Richards and Wiley, 1980; Gish and Morton, 1981; Shy and Morton 1986), but without compensating for the contribution of background noise to the amplitude values.

The present study concerns blackbird full songs, which are composed of a motif part with relatively low-frequency sounds $(1.5-3 \mathrm{kHz})$ and a subsequent twitter part covering a broad frequency range $(1.5-8 \mathrm{kHz}$ ) (e.g., Dabelsteen, 1984). The blackbird's song encompasses a very large selection of different sound types (Fig. 1), including types used by many other species. The large repertoire of sound types was one reason for choosing the blackbird song as the experimental subject. The other reason was that only in this territorial song bird species has the directionality of song emission (Larsen and Dabelsteen, 1990), as well as all the basic song parameters including those of amplitude and frequency patterns been measured and tested for signal value in both sexes (Dabelsteen and Pedersen, 1985a, 1988a,b, 1992, 1993). Knowledge of the directionality of song emission is a prerequisite for the choice of a loudspeaker with a similar directionality (e.g., Michelsen, 1978; Waser and Brown, 1984). Knowledge of the information carrying parameters and their importance to the two sexes is also necessary to obtain information about how well the song is adapted to resist environmental degradation.

We examine two issues. First, are blackbirds able to counteract degradation of the song by choosing optimal perches? Second, do blackbirds use song types or song features that correlate with their ability to resist degradation. The degradation of natural song is determined by measuring both the blurring, the excess attenuation and the $S / N$, and these measurements are performed concomitantly with a new computer program which allows compensation for background noise in the amplitude values. We do not aim to investigate the physical mechanisms producing the sound degradation. We quantify some of the problems which the auditory system of the blackbirds must solve.

\section{METHODS}

\section{A. Field recordings}

The test tape was broadcast and rerecorded in the mixed beech primeval forest at Strødam Biological Field Station. The forest is dominated by 30 -m-high beeches, which have trunks reaching a diameter of $0.4-0.7 \mathrm{~m}$ and canopies starting about $10 \mathrm{~m}$ above the ground. On average, the trunks are spaced $10 \mathrm{~m}$ apart. The area below the canopies is sparse with occasional dense undergrowth of bushes and young trees of various heights and species. The uneven ground is covered by grass and herbs, leaf litter, and fallen trees. The forest has many blackbirds, and it is reasonable to assume that this is an original type of blackbird habitat, e.g., Stephan (1985). Most blackbird territories have diameters ranging from about 30 to more than $100 \mathrm{~m}$. Full song is typically emitted from posts on the outermost branches of the underside of the canopy, from the top of the undergrowth, or, occasionally, from a lower height. The pure twitter song is emitted from all heights. Receivers high above the ground are usually other singing males, while both sexes may receive songs in the undergrowth and on the ground.

The relative speaker and microphone positions were chosen to represent typical blackbird song posts, and rival and female positions inside and outside territories in the above forest. The sounds of the test tape were recorded under a complete $2 \times 3 \times 5$ factorial design, i.e., with the speaker at 3 and $9 \mathrm{~m}$ above the ground, the microphone at $0.2,3$, and $9 \mathrm{~m}$ above ground and at distances of 25,50 , 100,150 , and $200 \mathrm{~m}$ from the speaker. These recordings supplied the observation sound for the data analysis. Since a speaker will always contribute to the degradation of the sounds, test tapes were also recorded close to the speaker (both speaker and microphone $9 \mathrm{~m}$ above the ground, distance between speaker and microphone $1.56 \mathrm{~m}$ ), where only negligible habitat-caused degradation could have taken place. For the speaker used for playback, the transition between the acoustic near field and the acoustic far field at $10 \mathrm{kHz}$ takes place at $60 \mathrm{~cm}$ (pp. 175-177 in Kinsler and Frey, 1962). This recording was taken as the reference or model sound for the data analysis.

All of the recordings were made in a single vertical plane. The distribution of vegetation in this plane (tree trunks of different diameters, branches, undergrowth, etc.) was representative for the habitat. The horizontal direction of the plane formed an angle of about $45^{\circ}$ to a road some 5-600 $\mathrm{m}$ away, i.e., the distance to the road and the extent of the forest between road and microphone were greatest at the microphone distance of $25 \mathrm{~m}$ and smallest at that of $200 \mathrm{~m}$. The background noise was approximately 30 $\mathrm{dB}(\mathrm{A})$ during the measurements. Part of the background noise came from the traffic on the road. However, we did not analyze recordings with time varying noise such as noise produced by passing cars and airplanes, or vocalizing birds.

The recordings were made under uniform conditions (wind speed $<0.9 \mathrm{~m} / \mathrm{s}$, relative humidity $47 \%-68 \%$, temperature $2^{\circ}-9^{\circ} \mathrm{C}$-measured at all heights), and after leaf fall in the middle of November. This simulated the physical conditions of early spring without masking from vocalizing birds.

The sounds were broadcast from a Sony TC-510-2 tape recorder (tape speed $19 \mathrm{~cm} / \mathrm{s}$, frequency response 30$20000 \mathrm{~Hz} \pm 1 \mathrm{~dB}$ ) through a Nagra DSM speaker (DSM). The DSM output was adjusted to a SPL of 63 $\mathrm{dB}(\mathrm{A})$ at a distance of $10 \mathrm{~m}$, which is the average level of the full blackbird dawn song (Dabelsteen, 1981). The directionality of the DSM was similar to that of the blackbird (Dabelsteen, 1981; Larsen and Dabelsteen, 1990). The DSM was suspended from a lateral branch of a large beech facing away from the trunk (distance to closest branch $>2.5 \mathrm{~m}$; distance to trunk $5.5 \mathrm{~m}$ ) and fixed in position. The recordings were made with a 1 -in. Brüel \& Kjær microphone (type 4145) connected to a Sony TC510-2 tape recorder (tape speed $19 \mathrm{~cm} / \mathrm{s}$ ) through a Brüel \& Kjær (type 2619) preamplifier and a Brüel \& Kjær (type 2606) measuring amplifier (high pass $22.6 \mathrm{~Hz}$ ). The 


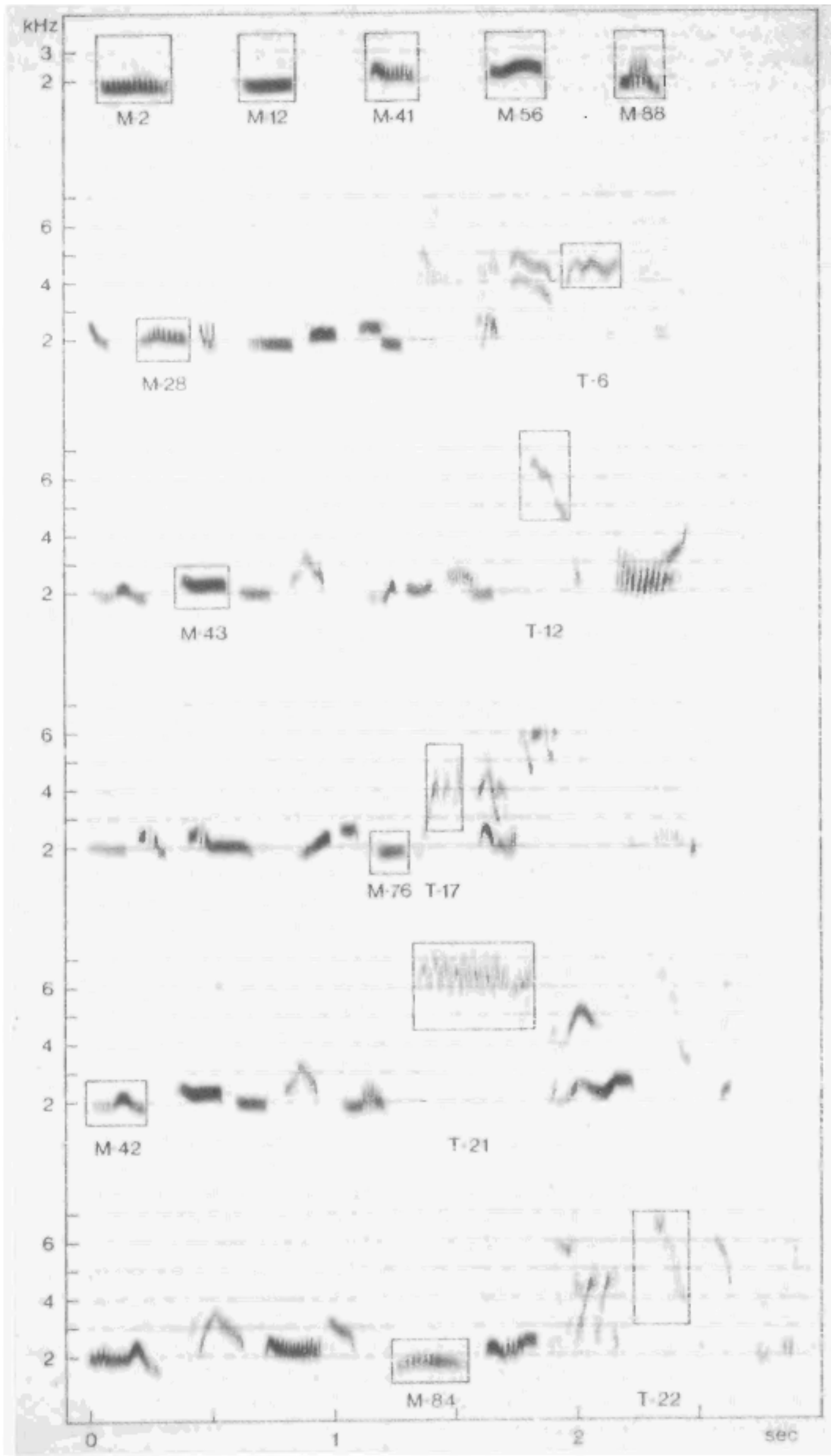

FIG. 1. Sonagrams of the model sounds. M: motif part sounds, T: twitter part sounds. Boxes indicate filter bandwidths used at the digital filterings of the enclosed sounds, see text. The sonagrams were made with a Kay Elemetrics Corp DSP 5500 sonagraph (bandwidth-300 Hz, frequency range$0-8000 \mathrm{~Hz}$ ). 


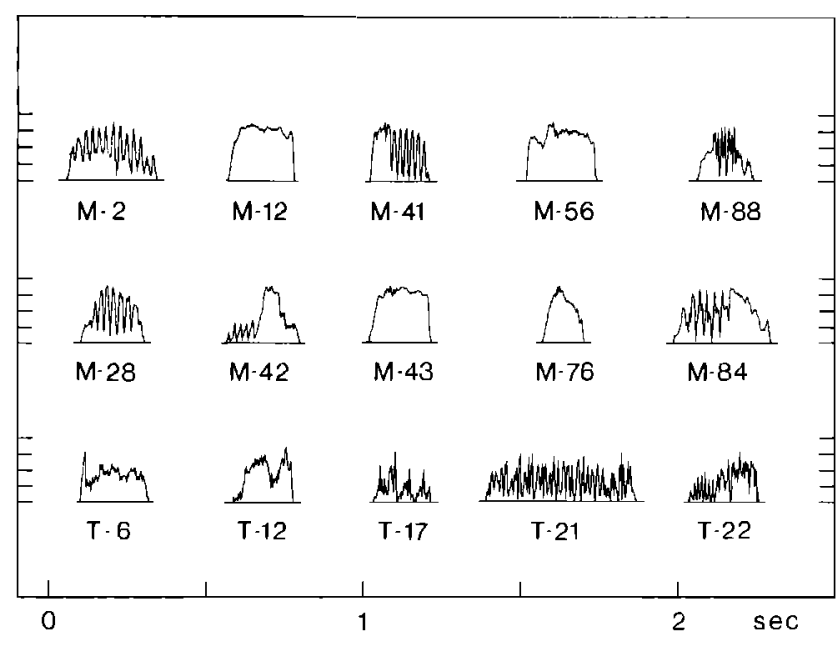

FIG. 2. Amplitude functions (envelopes) of the test sounds' model versions. M: motif part sounds, $T$ : twitter part sounds. The scales of the ordinates are linear. The sounds have been analyzed with different amplifications.

noise produced by the equipment was about $16 \mathrm{~dB}(\mathrm{~A})$. This ensured a measuring accuracy $\leqslant 1 \mathrm{~dB}$ [a $1-\mathrm{dB}$ accuracy was obtained at the $30 \mathrm{~dB}(\mathrm{~A})$ sound-pressure level of the background noise]. An oscilloscope inserted between amplifier and tape recorder allowed an on-line control of the recordings. The wind shielded (Brüel \& Kjær type 0207 wind-screen) microphone was fixed in a horizontal position on top of a telescopic Clark Mast (type QT 9M/ HP) or a photo tripod, pointing directly towards the DSM.

\section{B. Test sounds}

The test tape contained two sections separated by a pause of $5 \mathrm{~s}$. The first section had five different motif part sounds, M-2, M-12, M-41, M-56, and M-88 (Figs. 1 and 2) each repeated five times. The inter-repetition pause was $0.23 \mathrm{~s}$, more than twice the average natural length of the pauses between motif part sounds. The pause between each type of sound was $3 \mathrm{~s}$ and similar to the normal intersong pause (Dabelsteen, 1984). The second section had a 2-min recording of 28 different songs. The test sounds of both sections had been recorded less than $3 \mathrm{~m}$ from a singing bird. We analyzed the entire recording of the first section. From the second section, we selected five motif (M-28, M-42, M-43, M-76, and M-84) and five twitter part sounds (T-6, T-12, T-17, T-21, and T-22) contained within five songs for analysis (Figs. 1 and 2). From the pause between the two sections, we selected $1 \mathrm{~s}$ for estimation of the background noise assuming that the background noise here would be similar to that existing during the test sounds. To make this assumption more likely, we made sure that neither pause sections nor test sounds were "masked" by randomly occurring transient fluctuations, loud noises, or bird vocalization. All the test sounds were played back at their natural SPL (Dabelsteen, 1981).

The 15 test sounds were representative. Motif sounds may be divided into CF figures with a relatively constant frequency, MIX figures with part of the sound being well modulated, and FM figures with the entire sound well modulated (Dabelsteen and Pedersen, 1992). Forty percent of the present motif sounds were CF figures (M-12, M-43, M-56, M-76), 40\% were MIX figures (M-41, M-42, M-84, M-88), and 20\% were FM figures (M-2, M-28). This corresponds to the distribution in normal blackbird song of $36 \% \mathrm{CF}, 43 \% \mathrm{MIX}$, and $21 \%$ FM figures (Dabelsteen and Pedersen, 1992). A similar categorization of twitter sounds has not been performed. Twitter sounds were chosen to be without overtones. Some covered rather narrow, others rather broad frequency ranges. Together, they covered the normal frequency range of twitter sounds (Dabelsteen, 1984).

\section{Data analysis}

The blackbird sound signal $g_{a}(t)$ can be modeled as the product of two signals

$$
g_{a}(t)=g(t) b(t)
$$

where $b(t)$ accounts for the variation in frequency of the signal and $g(t)$ is the amplitude or envelope function (AF) of the signal. As

$$
b(t)=\cos (\psi(t))
$$

where $\psi(t)$ is a suitable function of time, has the amplitude 1 , the slowly varying amplitude of the blackbird sounds is described solely by $g(t)$.

The transmission of $g_{a}(t)$ through a simple frequencyindependent and noise-free channel results in an observed signal

$$
y_{a}(t)=k_{a} g_{a}(t),
$$

where the constant $k_{a}$ models the total attenuation of the channel. Under these ideal circumstances the AF, $y(t)$, of the observed signal is

$$
y(t)=k_{a} g(t) .
$$

In practice, the channel exhibits both frequency-dependent and multipath transmission properties, and the observed AF, $y(t)$, is no longer proportional to the AF $g(t)$. One now has

$$
y(t)=k g(t)+x(t)
$$

where $k$ represents the mean attenuation of the channel during transmission of $g_{a}(t)$, and $x(t)$ represents the observed blurring of the transmitted AF. The determination of $k$, and thus of $x(t)$, may be carried out by minimizing the energy $E_{x}$ of $x(t)$. Note that $x(t)$ is not an AF since it may also take negative values.

The excess attenuation in $\mathrm{dB}$ is now defined as

$$
-(20 \log k-A),
$$

where $A$ is the attenuation in $\mathrm{dB}$ caused by geometric spreading. For a point source, this amounts to $6 \mathrm{~dB}$ per doubling of the distance between sound source and sound receiver.

The blur ratio is defined as

$$
E_{x} / E_{y} \text {, }
$$


where $E_{y}$ is the energy of the observed signal. If the channel is corrupted by additive stationary noise the observed energy $E_{y}$ is the sum of the energy of the blackbird sound and the energy $E_{n}$ of the noise over the duration of the observation. Consequently, the signal-to-noise ratio $(\mathrm{S} / \mathrm{N})$ in $\mathrm{dB}$ is defined as

$$
10 \log \left(\left(E_{y}-E_{n}\right) / E_{n}\right) \text {. }
$$

This equation calls for determination of $E_{n}$ during a time interval where no blackbird sound is present.

For $\mathrm{S} / \mathrm{N}$ below approximately $20 \mathrm{~dB}$, the determination of $k$ and $E_{x}$ is complicated by the fact that the AF of the noise combines with the AF of the blackbird sound in a nonlinear fashion, and an exact determination of $x(t)$ is impossible. However, as the blur ratio is based on energies, it is possible to make corrections for the influence of the noise assuming that the noise and the signal are stochastically independent. Further details of this theory are given in Pedersen et al. (in preparation).

The blur ratio, excess attenuation, and $\mathrm{S} / \mathrm{N}$ are representative measures of the changes in the majority of the known information carrying parameters in the sounds. For example, changes in blur ratio alone reflect changes in both amplitude and frequency patterns over time. The relative energies of the fundamental and its overtones, however, are not included in the present compound degradation measure. The relative-energy parameter may carry information on emitter identity or motivation in the blackbird (Dabelsteen and Pedersen, 1992, 1993), and it may bear special importance to birds using sounds with energy-rich overtones, e.g., to nonpasserines species. In these species, it is necessary to quantify transmission changes of the power spectra of sounds. To the test sounds of the present study (fundamentals without overtones), this supplementary measure is less relevant. Also, a major complication of using the average power spectrum measure is the problem of the compensation for the influence of the background noise, which has been solved in the computation of the present three measures of degradation.

\section{Data analysis practice}

The duration of an observed sound is virtually always longer than that of the corresponding model sound, since echoes prolong the propagating sound (Fig. 3 ). In calculating the blur ratio, we have disregarded the tail because it is questionable whether the tail provides any additional type of information. The tail may be correlated with propagation distance and give the receiving bird some additional information in ranging, but such information is also inherent in the blurring of the "model part" of the observed sound (cf. Richards, 1981; Morton, 1982; McGregor et al., 1983; McGregor and Falls, 1984; McGregor and Krebs, 1984; McGregor, 1991). Another consequence of the existence of the tail is its possible masking of successive sounds. The present study used unnaturally long pauses between the repeated motif sounds and therefore the effect of the tail has been minimal.

The sound analysis was done on a DEC micro-VAX computer using specially developed programs. The record-
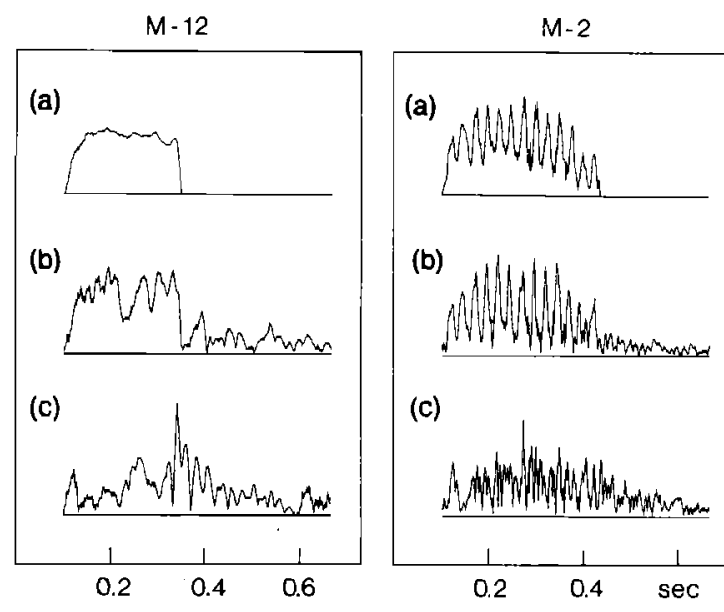

(b)

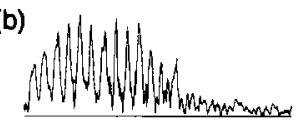

(c)

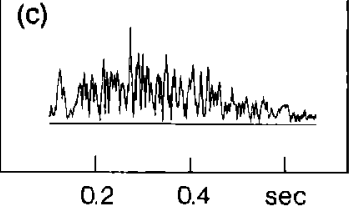

FIG. 3. Amplitude functions of motif part sounds $M-2$ and M-12: (a) models, (b) observations with a small blur ratio (M-2: 0.073, M-12: 0.045 ), (c) observations with a large blur ratio (M-2: 0.342, M-12: 0.239 ). Parts (b) and (c) were broadcast from the speaker $3 \mathrm{~m}$ above ground and observed at a distance of $25 \mathrm{~m}$, with the microphone 9 and 3 m above ground, respectively.

ings were first filtered (Rockland model 852 , low-pass: 8 $\mathrm{kHz}, 24 \mathrm{~dB} / \mathrm{oct}$ ) and then digitized using a sampling time interval of $50 \mu \mathrm{s}$. The AF's of model sounds (Fig. 2), observation sounds, and 1-s pause sections with background noise were obtained through a number of steps involving digital filtering and a Hilbert transformation as shown on flow diagrams in Dabelsteen and Pedersen (1985b). The digital filterings were performed with filter bandwidths and center frequencies ensuring that the AF's used in the comparison had a frequency range limited to that of the actual model sound (Fig. 1) (Table I).

For each of the 15 test sounds, the observations were successively compared with their respective models through the following steps. (1) The energy of the background noise during a time interval corresponding to the duration of the model was determined without the presence of the blackbird sound. (2) The AF's of model and observation were aligned in time by maximizing the cross correlation between them. (3) In the aligned position, the energy of the observation was determined and the $\mathrm{S} / \mathrm{N}$

TABLE I. Nine different filter settings, filter bandwidth, center frequency, and frequency range, used for the digital filtering of test sounds and background noise, see text.

\begin{tabular}{lccc}
\hline \hline Test sound & $\begin{array}{c}\text { Bandwidth } \\
(\mathrm{kHz})\end{array}$ & $\begin{array}{c}\text { Center frequency } \\
(\mathbf{k H z})\end{array}$ & $\begin{array}{c}\text { Frequency range } \\
(\mathrm{kHz})\end{array}$ \\
\hline M-2, M-12, M-41, & & & \\
M-56 and M-88 & 2.4 & 2.4 & $1.20-3.60$ \\
M-28 and M-42 & 1.5 & 2.0 & $1.25-2.75$ \\
M-43 & 1.5 & 2.2 & $1.45-2.95$ \\
M-76 and M-84 & 1.5 & 1.8 & $1.05-2.55$ \\
T-6 & 1.5 & 4.5 & $3.75-5.25$ \\
T-17 & 3.0 & 4.0 & $2.50-5.50$ \\
T-12 and T-21 & 3.0 & 6.0 & $4.50-7.50$ \\
T-22 & 4.0 & 5.0 & $3.00-7.00$ \\
\hline \hline
\end{tabular}


computed. (4) For $\mathrm{S} / \mathrm{N}$ greater than $20 \mathrm{~dB}$, the squared difference between the observed $\mathrm{AF}$ and $k$ times the model $\mathrm{AF}$ was minimized, and $k$ and the difference signal determined. For $\mathrm{S} / \mathrm{N}$ smaller than $20 \mathrm{~dB}$ the procedure was somewhat more involved, see Pedersen et al. (in preparation). (5) From the knowledge of $k$, the excess attenuation was computed. (6) The energy of the difference signal was finally used to determine the blur ratio.

The actual determination of the energies of the different signals was carried out as summations over squared digitized AF values. As the significant part of the energy of a blackbird song AF is contained in the frequency band below-in most cases far below- $1 \mathrm{kHz}$, a sampling time interval of $400 \mu \mathrm{s}$ was used for the AF. Furthermore, the probable time resolution capacity of the blackbird auditory system is assumed to be greater than $1 \mathrm{~ms}$ as found in other passerines (e.g., Dooling, 1982; Klump and Maier, 1989).

\section{E. Statistics}

The data on degradation of M-2, M-12, M-41, M-56, and M-88 were pooled for statistical tests. At a distance of $200 \mathrm{~m}$, the received signal could not be analyzed since the very low $\mathrm{S} / \mathrm{N}$ obtained here rendered the alignment of the models and observations dubious. Five repetitions of M-41 at $150 \mathrm{~m}$ were rejected because of masking from loud vocalizations. The blur ratio, the excess attenuation (in $\mathrm{dB}$ ) and the $\mathrm{S} / \mathrm{N}$ (in $\mathrm{dB}$ ) were measured for the remaining 595 observations, and the data for each of the three measures was subjected to a $2 \times 3 \times 4 \times 5$ factorial ANOVA (two speaker heights, three microphone heights, four microphone distances, five sounds) with five replications. Only main and two-factor interaction effects were considered. In order to test the relationship between the three measures, the product moment correlation coefficients $(r)$ were calculated for each pair of measures and their significance tested.

The degradation measures of M-28, M-42, M-43, M-76, M-84, T-6, T-12, T-17, T-21, and T-22 were also pooled for analysis, but only for values collected at $25 \mathrm{~m}$. The $\mathrm{S} / \mathrm{N}$ of the twitter sounds was only sufficiently high at $25 \mathrm{~m}$ to make the uncertainty of the alignment of the models and observations as low as that for the motif sounds. As before, the data for each of the three degradation measures were subjected to an ANOVA, i.e., to a $2 \times 3 \times 10$ factorial ANOVA (two speaker heights, three microphone heights, ten sounds), and only main and two-factor interaction effects were considered. The relationship between the three measures was tested by calculating Spearman's correlation coefficients $(r s)$ for each pair of measures and testing for significance.

In order to test the variation in background noise level, we selected the data of four representative filter settings for analysis: (1) $1.20-3.60 \mathrm{kHz}$, (2) $2.50-5.50 \mathrm{kHz}$, (3) $3.75-$ $5.25 \mathrm{kHz}$, and (4) $4.50-7.50 \mathrm{kHz}$ (cf. Table I). The data were subjected to a $2 \times 3 \times 4 \times 4$ factorial ANOVA (two speaker heights, three microphone heights, four microphone distances, and four filter settings). Only main and two-factor interaction effects were considered.
TABLE II. ANOVA table for background noise level $(2 \times 3 \times 4 \times 4$ factorial ANOVA, two speaker heights, three microphone heights, four microphone distances, four filter settings, $N=96$ ).

\begin{tabular}{lrrr}
\hline \hline Source of variation & d.f. & \multicolumn{1}{c}{$F$ ratio } & \multicolumn{1}{c}{$\boldsymbol{P}$} \\
\hline Main effects & 9 & 26.509 & $<0.0001$ \\
$\quad$ Speaker height & 1 & 0.048 & 0.8305 \\
$\quad$ Microphone height & 2 & 6.132 & 0.0039 \\
$\quad$ Microphone distance & 3 & 13.537 & $<0.0001$ \\
$\quad$ Filter setting & 3 & 61.887 & $<0.0001$ \\
$\begin{array}{l}\text { Two-factor interactions } \\
\begin{array}{l}\text { Speaker height by } \\
\text { microphone height }\end{array}\end{array}$ & 29 & 2.493 & 0.0016 \\
$\begin{array}{l}\text { Speaker height by } \\
\text { microphone distance }\end{array}$ & 3 & 0.263 & 0.7699 \\
$\begin{array}{l}\text { Microphone height } \\
\text { by microphone distance }\end{array}$ & 6 & 7.469 & 0.2325 \\
$\begin{array}{l}\text { Speaker height by } \\
\text { filter setting }\end{array}$ & 3 & 0.084 & 0.9685 \\
$\begin{array}{l}\text { Microphone height by } \\
\text { filter setting }\end{array}$ & 6 & 2.083 & 0.0694 \\
$\begin{array}{l}\text { Microphone distance by } \\
\text { filter setting }\end{array}$ & 9 & 0.959 & 0.4831 \\
\hline \hline
\end{tabular}

All statistical calculations were performed with the Statgraphics statistical package from STSC, Inc.

\section{RESULTS}

\section{A. Relative variation in background noise level}

As expected, the ANOVA on the background noise level showed no significant effect for speaker height (Table II). The main effects for the remaining factors, however, were all significant. Only one of the six two-factor interactions was significant, microphone height by microphone distance (Table II). Together, the main effects and the two-factor interactions explained $84.5 \%$ of the variation.

A subsequent multiple range analysis using the $95 \%$ confidence intervals for factor means showed that the noise at the microphone heights 0.2 and $9 \mathrm{~m}$ were reliably different, the level at $9 \mathrm{~m}$ being highest (Table III). As re-

TABLE III. Variation in background noise level with microphone height, microphone distance, and filter setting. Noise levels of the different heights, distances, and filter settings are given as deviations in $\mathrm{dB}$ from the levels of the respective height, distance and filter setting with the lowest noise levels.

\begin{tabular}{lcc}
\hline \hline Source of variation & & $\begin{array}{c}\text { Deviation } \\
(\mathrm{dB})\end{array}$ \\
\hline Microphone height & $0.2 \mathrm{~m}$ & $+1,1$ \\
& $3.0 \mathrm{~m}$ & +2.2 \\
& $9.0 \mathrm{~m}$ & \\
Microphone distance & $25 \mathrm{~m}$ & +3.1 \\
& $50 \mathrm{~m}$ & +2.0 \\
& $100 \mathrm{~m}$ & +4.7 \\
Filter setting & $150 \mathrm{~m}$ & \\
& $3.75-5.25 \mathrm{kHz}$ & +1.1 \\
& $4.50-7.50 \mathrm{kHz}$ & +4.1 \\
& $2.50-5.50 \mathrm{kHz}$ & +8.5 \\
\hline \hline
\end{tabular}


TABLE IV. ANOVA table for blur ratio $(2 \times 3 \times 4 \times 5$ factorial ANOVA, two speaker heights, three microphone heights, four microphone distances, five sounds (motif sounds M-2, M-12, M-41, M-56, and M-88, $N=595$ ).

\begin{tabular}{lrrr}
\hline \hline Source of variation & d.f. & \multicolumn{1}{c}{$F$ ratio } & \multicolumn{1}{c}{$\boldsymbol{P}$} \\
\hline Main effects & 10 & 57.128 & $<0.0001$ \\
Speaker height & 1 & 0.053 & 0.8202 \\
Microphone height & 2 & 129.242 & $<0.0001$ \\
Microphone distance & 3 & 67.453 & $<0.0001$ \\
Sound & 4 & 30.814 & $<0.0001$ \\
Two-factor interactions & 35 & 14.994 & $<0.0001$ \\
$\quad$ Speaker height by & 2 & 15.970 & $<0.0001$ \\
microphone height & & & \\
Speaker height by & 3 & 10.781 & $<0.0001$ \\
microphone distance & & & \\
$\begin{array}{l}\text { Microphone height by } \\
\text { microphone distance }\end{array}$ & 6 & 27.937 & $<0.0001$ \\
$\begin{array}{l}\text { Speaker height by sound } \\
\text { Microphone height by sound }\end{array}$ & 4 & 16.331 & $<0.0001$ \\
Microphone distance by sound & 12 & 17.320 & $<0.0001$ \\
\hline \hline
\end{tabular}

gards microphone distance the background noise level differed reliably only between 25 and $150 \mathrm{~m}$, the latter being highest (Table III). The noise level varied reliably between three groups of filter settings. The highest noise level was measured with the filter setting $1.2-3.6 \mathrm{kHz}$. The second highest level was measured with the setting $2.5-5.5 \mathrm{kHz}$. The lowest levels were measured with the settings 4.5-7.5 $\mathrm{kHz}$ and $3.75-5.25 \mathrm{kHz}$ (Table III).

The two-factor means showed among other things that the background noise level varied most with distance at a microphone height of $9 \mathrm{~m}$, but less at the other heights (8.8, 3.8, and 5.6 dB at 9, 3, and $0.2 \mathrm{~m}$, respectively).

\section{B. Degradation of motif sounds $M-2, M-12, M-41$, $M-56$, and $M-88$}

\section{Blur ratio}

Examples of how amplitude functions of M-2 and M-12 look when the sounds are subjected to a relatively high and low degree of blurring, are shown in Fig. 3. The ANOVA on the blur ratio showed significant main effects for microphone height, microphone distance, and sound type, but not for speaker height (Table IV). The effects of the six two-factor interactions, however, were all significant. Together, the main effects and the two-factor interactions explained $67 \%$ of the variation. The subsequent multiple range analysis showed that the three microphone heights were all different with the lowest blur ratio occurring at $9 \mathrm{~m}$ above ground and the highest at $3 \mathrm{~m}$ [Fig. 4(b)]. The microphone distances could be divided into three groups. The blur ratio was almost equal for 50 and $150 \mathrm{~m}$, whereas it was higher at $100 \mathrm{~m}$, but smaller at $25 \mathrm{~m}$ [Fig. 4(c)]. The sounds could be divided into two homogeneous groups, M-12 and M-56 with the lowest blur ratio, and M-2, M-41, and M-88 with the highest [Fig. 4(d)].

The two-factor means showed among other things that the blur ratio was relatively high and varied little with distance at a microphone height of $3 \mathrm{~m}$, while the variation was considerable at a height of $9 \mathrm{~m}$ (Fig. 5). Another
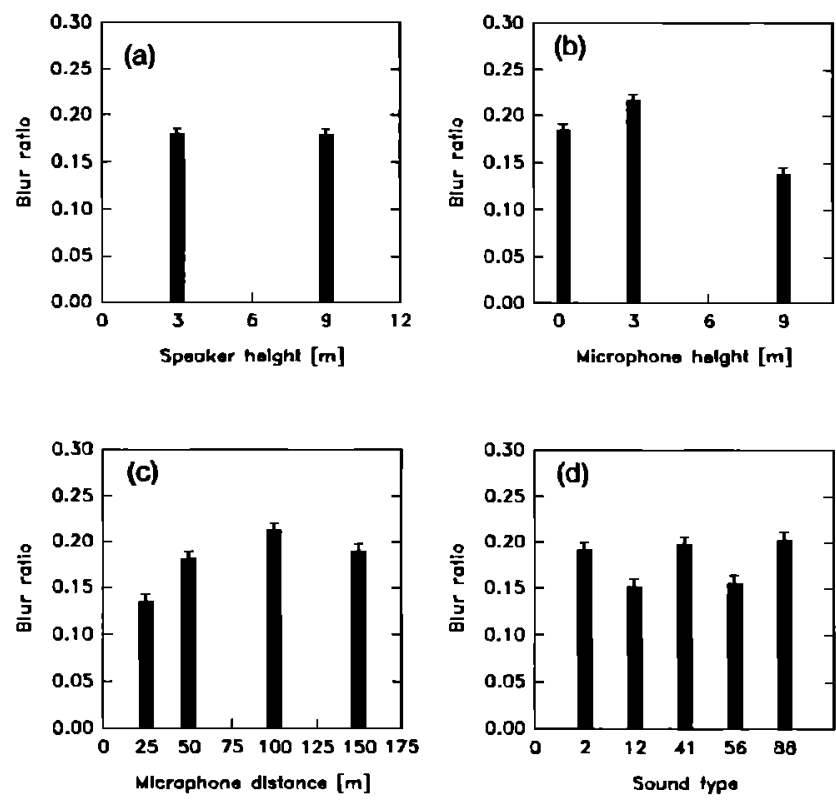

FIG. 4. The blur ratio of motif sounds $M-2, M-12, M-41, M-56$, and M-88 analyzed in a four-way factorial ANOVA, showing levels of main factor effects: (a) speaker height, (b) microphone height, (c) microphone distance, and (d) sound type. Error bars: $95 \%$ confidence intervals for factor means.

interesting point was the fact that within the two homogeneous groups of sounds the mutual ranking of the sounds' blur ratio varied with both the speaker height, the microphone height and the microphone distance.

\section{Excess attenuation}

The ANOVA on the excess attenuation showed significant main effects for all four factors (Table V). The effects of the six two-factor interactions were also significant. Together, the main effects and the two-factor interactions explain more than $90 \%$ of the variation. The multiple range analysis again showed that the three microphone heights

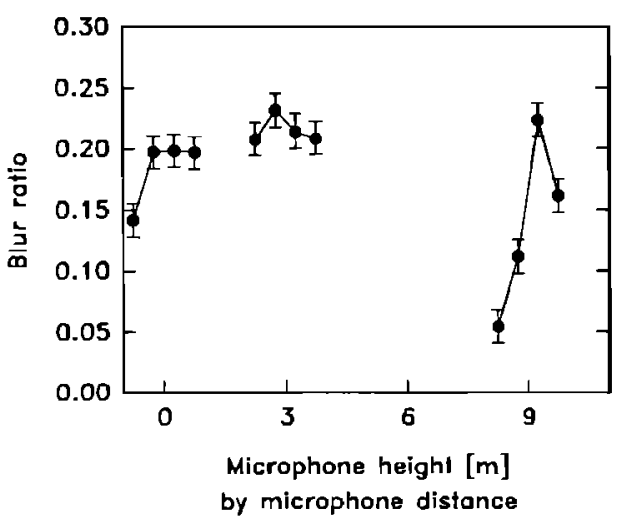

FIG. 5. The blur ratio of motif sounds $M-2, M-12, M-41, M-56$, and M-88 analyzed in a four-way factorial ANOVA, showing an example of the levels of two-factor interaction effects: microphone height by microphone distance. The three clusters of datapoints joined with straight lines indicate the three microphone heights, $0.2,3$, and $9 \mathrm{~m}$ (abscissa). Each cluster is ordered such that the leftmost datapoint indicates the smallest value of the second factor (microphone distance), successively increasing to the right as follows: 25, 50, 100, and $150 \mathrm{~m}$. Error bars as in Fig. 4. 
TABLE V. ANOVA table for excess attenuation. Details as in Table IV.

\begin{tabular}{lrrr}
\hline \hline Source of variation & d.f. & $F$ ratio & $P$ \\
\hline Main effects & 10 & 393.584 & $<0.0001$ \\
Speaker height & 1 & 127.183 & $<0.0001$ \\
Microphone height & 2 & 595.853 & $<0.0001$ \\
Microphone distance & 3 & 852.115 & $<0.0001$ \\
Sound & 4 & 15.780 & $<0.0001$ \\
& 35 & 37.665 & $<0.0001$ \\
Two-factor interactions & 2 & 39.972 & $<0.0001$ \\
Speaker height by microphone height & 3 & 74.620 & $<0.0001$ \\
Speaker height by & & & \\
microphone distance & 6 & 123.318 & $<0.0001$ \\
Microphone height by & & & \\
microphone distance & 4 & 3.612 & 0.0064 \\
Speaker height by sound & 8 & 10.862 & $<0.0001$ \\
Microphone height by sound & 12 & 15.070 & $<0.0001$ \\
\hline Microphone distance by sound & & & \\
\hline \hline
\end{tabular}

were all different. The 9-m height had the lowest excess attenuation, while $0.2 \mathrm{~m}$ had the highest [Fig. 6(b)]. The excess attenuation clearly differed between the four microphone distances, increasing almost linearly with distance [Fig. 6(c)]. Sounds could be divided into two homogeneous groups, but different from those for blur ratio, i.e., M-2 and M-12 with the lowest excess attenuation and M-41, M-56, and M-88 with the highest one [Fig. 6(d)].

Regarding the two-factor means, the excess attenuation seems to show some of the same trends as blur ratio. For instance, the excess attenuation varied the least with distance at a microphone height of $3 \mathrm{~m}$, but the highest variation and the highest mean was found at a height of 0.2 $\mathrm{m}$ [Fig. 7(a)]. Additionally, the mutual ranking of excess attenuations of sounds varied with the three other factors within both of the two groups of sounds. Interestingly, the variation of excess attenuation between sounds seemed to be smallest at a microphone height of $3 \mathrm{~m}$ [Fig. 7(b)].
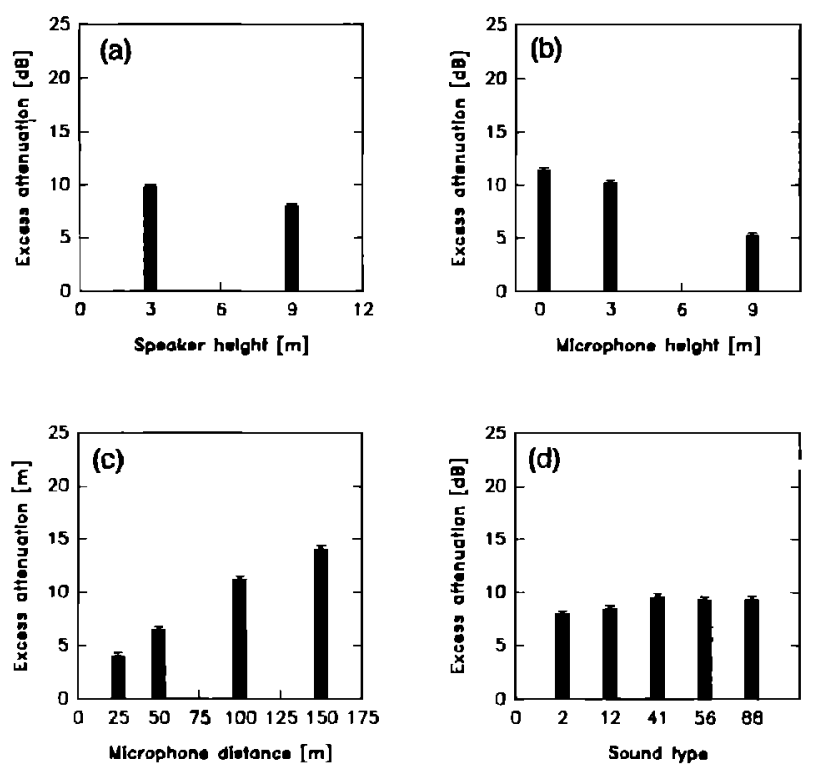

FIG. 6. The degree of excess attenuation of motif sounds M-2, M-12, M-41, M-56, and M-88 analyzed in a four-way factorial ANOVA, showing levels of main factor effects. Nomenclature as in Fig. 4.
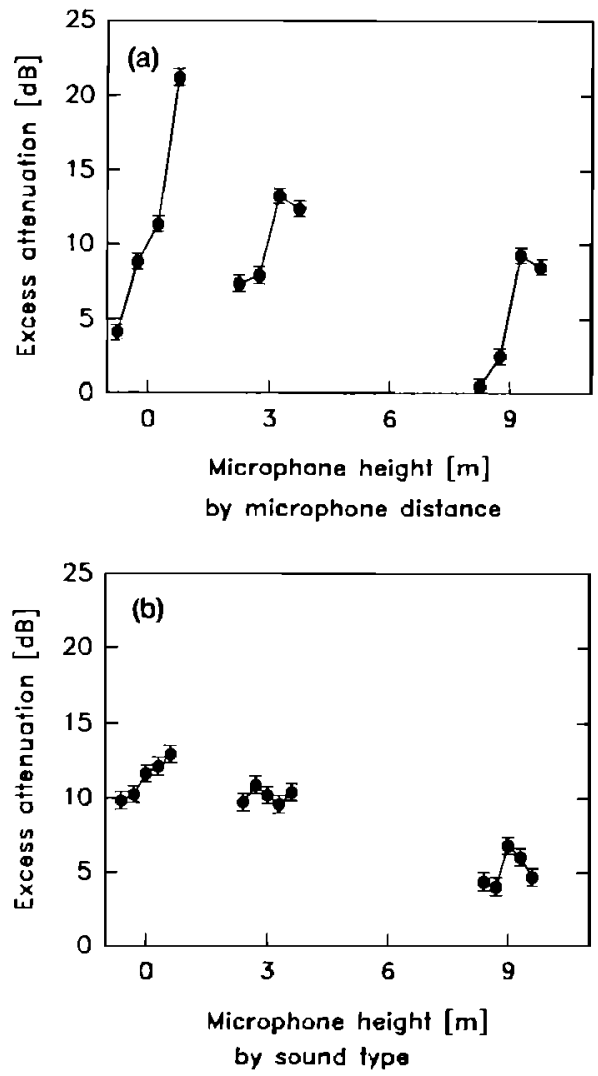

FIG. 7. The degree of excess attenuation of motif sounds M-2, M-12, M-41, M-56 and M-88 analyzed in a four-way factorial ANOVA, showing two examples of levels of two-factor interaction effects: (a) microphone height by microphone distance; (b) microphone height by sound type. Nomenclature as in Fig. 5; however, in (b) each cluster is ordered such that the datapoints, from left to right, indicate the following sounds: $\mathbf{M - 2}$, $M-12, M-41, M-56$, and M-88.

\section{Signal-to-noise ratio (S/N)}

The ANOVA on the $\mathrm{S} / \mathrm{N}$ showed trends similar to those of the excess attenuation. The main effects of all four factors were significant and so were the effects of the twofactor interactions (Table VI). Together, the main effects

TABLE VI. ANOVA table for signal-to-noise ratio. Details as in Table IV.

\begin{tabular}{lrrr}
\hline \hline Source of variation & d.f. & \multicolumn{1}{c}{$F$ ratio } & $P$ \\
\hline Main effects & 10 & 1000.000 & $<0.0001$ \\
$\quad$ Speaker height & 1 & 64.704 & $<0.0001$ \\
Microphone height & 2 & 198.647 & $<0.0001$ \\
Microphone distance & 3 & 1000.000 & $<0.0001$ \\
Sound & 4 & 34.014 & $<0.0001$ \\
Two-factor interactions & 35 & 38.549 & $<0.0001$ \\
$\quad$ Speaker height by & 2 & 28.567 & $<0.0001$ \\
microphone height & & & \\
$\begin{array}{l}\text { Speaker height by } \\
\text { microphone distance }\end{array}$ & 3 & 104.628 & $<0.0001$ \\
$\begin{array}{l}\text { Microphone height by } \\
\text { microphone distance }\end{array}$ & 6 & 126.229 & $<0.0001$ \\
$\begin{array}{l}\text { Speaker height by sound } \\
\text { Microphone height by sound }\end{array}$ & 4 & 3.124 & 0.0147 \\
Microphone distance by sound & 12 & 13.137 & $<0.0001$ \\
\hline \hline
\end{tabular}



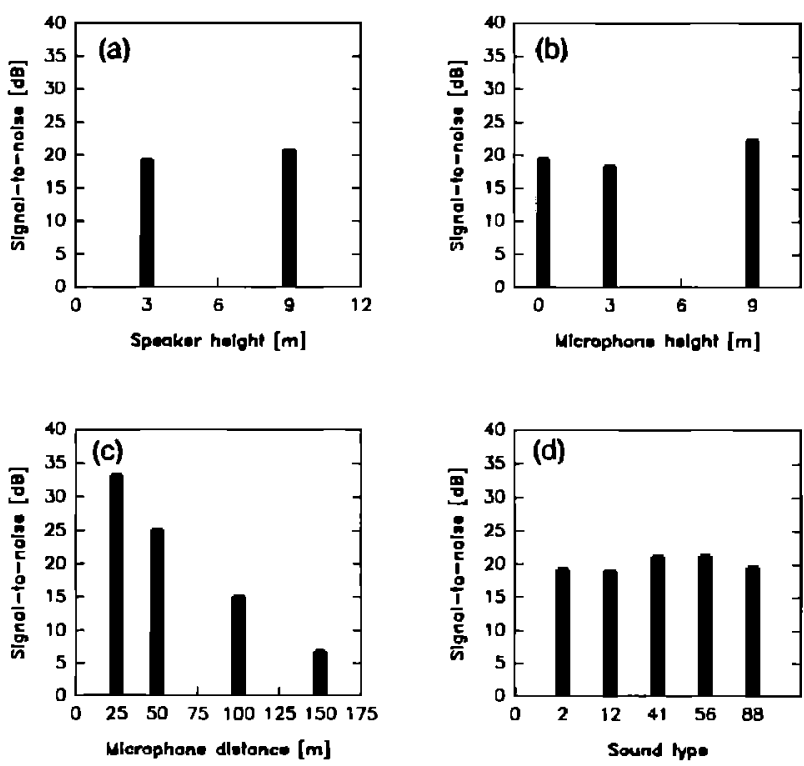

FIG. 8. The signal-to-noise ratio of motif sounds $M-2, M-12, M-41$, M-56, and M-88 analyzed in a four-way factorial ANOVA, showing levels of main factor effects. Nomenclature as in Fig. 4.

and two-factor interactions explained as much as $96 \%$ of the variation. In this case a single main effect, i.e., that of microphone distance, alone accounted for $84 \%$ of the variation.

Once again, the multiple-range analysis showed that the three microphone heights were all different. A microphone height of $9 \mathrm{~m}$ had the highest mean signal-to-noise ratio $(22.2 \mathrm{~dB}$ ), at $0.2 \mathrm{~m}$, the mean ratio was $19.3 \mathrm{~dB}$, while at a height of $3 \mathrm{~m}$, it was only $18.2 \mathrm{~dB}$ [Fig. 8(b)]. Interestingly, the signal-to-noise ratios would have been even lower than observed at 3 and $0.2 \mathrm{~m}$ (by 2.5 and 6.3 $\mathrm{dB}$, respectively) had the background noise level been equal at the three heights. The values for the four microphone distances clearly differed, decreasing almost linearly with distance [Fig. 8(c)]. Finally, the sounds could be divided into two homogeneous groups, i.e., M-41 and M-56 with the highest signal-to-noise ratio and $\mathrm{M}-2, \mathrm{M}-12$, and M-88 with the lowest one [Fig. 8(d)].

The two-factor means for signal-to-noise ratio again showed the highest variation with distance at a microphone height of $0.2 \mathrm{~m}$, where also the absolutely lowest mean ratio was observed (Fig. 9). As with blur ratio and excess attenuation the mutual ranking of the sounds' signal-to-noise ratios varied with the three other factors within each of the two groups of sounds.

\section{Correlations}

The three different measures of degradation were mutually correlated at $p<0.0001$. The highest correlation was found between excess attenuation and $S / N(r=-0.841)$, the lowest between blur ratio and $S / N(r=-0.406)$. The blur ratio was positively correlated with excess attenuation $(r=0.591)$.

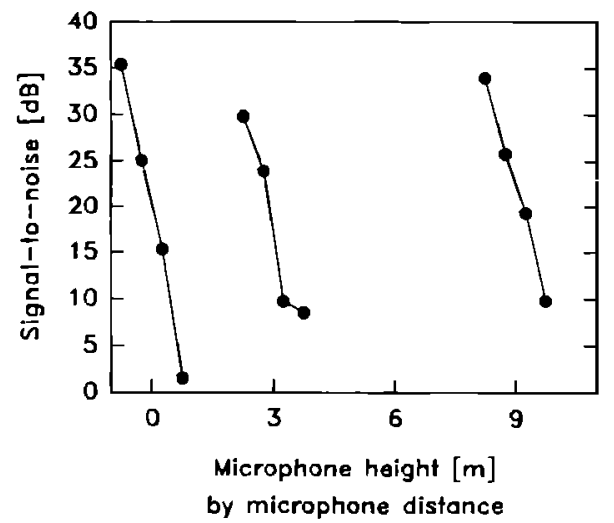

FIG. 9. The signal-to-noise ratio of motif sounds $M-2, M-12, M-41$, M-56, and M-88 analyzed in a four-way factorial ANOVA, showing an example of the levels of two-factor interaction effects: microphone height by microphone distance. Nomenclature as in Fig. 5 . Note that the confidence intervals are smaller than the datapoint symbols.

\section{Degradation of motif sounds $M-28, M-42, M-43$, $M-76$, and $M-84$, and twitter sounds T-6, T-12, T-17, $\mathrm{T}-21$, and T-22}

\section{Blur ratio}

The ANOVA on the blur ratio showed significant main effects for microphone height and sound (Table VII). The main effect of speaker height was not significant and the same applies to the three two-factor interactions. Together, the main effects and two-factor interactions explained more than $85 \%$ of the variation.

The multiple range analysis showed a reliable difference only between microphone heights of 9 and $3 \mathrm{~m}$ with the latter having the highest degree of blurring [Fig. $10(b)]$. T-21 and T-22 clearly differed from M-28, M-43, and M-76. The remaining twitter and motif sounds had mean values overlapping these two groups [Fig. 10(c)]. If, however, the three-way ANOVA was repeated with the number of levels for the factor sounds reduced to two (twitter and motif sounds), then the main effect of sounds would still be highly significant $(p<0.0001)$, and the mean blur ratio for twitter and motif sounds would be clearly different ( 0.213 and 0.125 , respectively). Note, that the

TABLE VII. ANOVA table for blur ratio $(2 \times 3 \times 10$ factorial design, two speaker heights, three microphone heights, ten sounds (motif sounds M-28, M-42, M-43, M-76 an M-84, and twitter sounds T-6, T-12, T-17, T-21 and T-22, $N=60$ ).

\begin{tabular}{lrcc}
\hline \hline Source of variation & d.f. & $F$ ratio & $P$ \\
\hline Main effects & 12 & 5.661 & 0.0006 \\
$\quad$ Speaker height & 1 & 2.859 & 0.1081 \\
Microphone height & 2 & 7.103 & 0.0053 \\
Sound & 9 & 5.652 & 0.0009 \\
Two-factor interactions & 29 & 1.286 & 0.2926 \\
Speaker height by & 2 & 0.499 & 0.6150 \\
microphone height & & & \\
Speaker height by sound & 9 & 0.472 & 0.8747 \\
Microphone height by sound & 18 & 1.780 & 0.1155 \\
\hline \hline
\end{tabular}



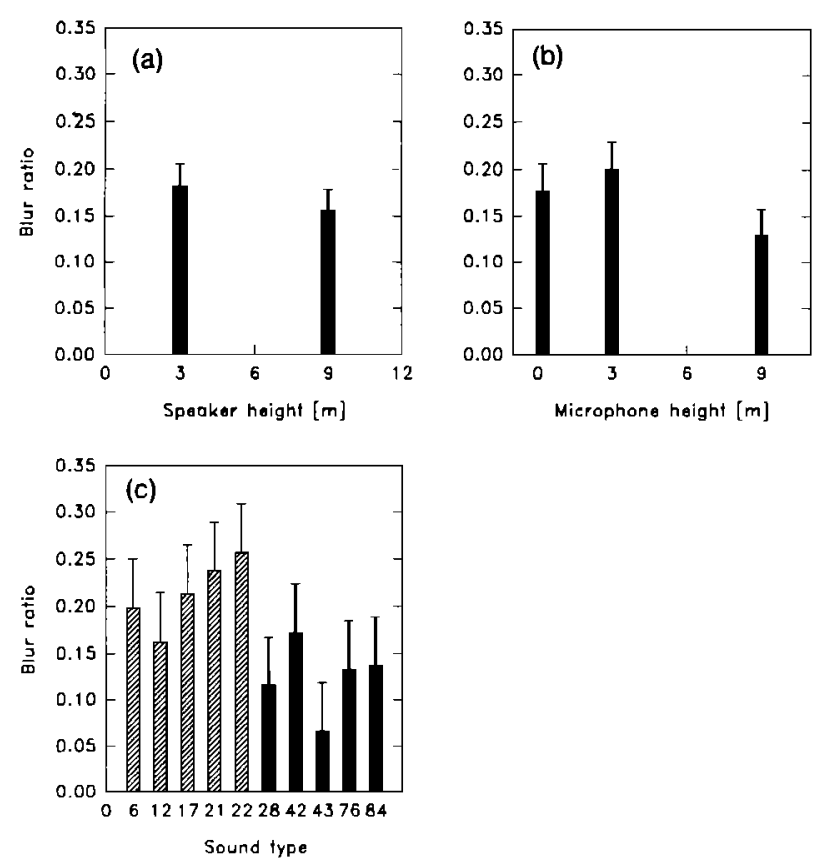

FIG. 10. The blur ratio of twitter sounds $T-6, T-12, T-17, T-21$, and $T-22$ and motif sounds M-28, M-42, M-43, M-76, and M-84 analyzed in a three-way factorial ANOVA, showing levels of main factor effects: (a) speaker height, (b) microphone height, and (c) sound type. Error bars as in Fig. 4.

0.125 for motif sounds is very close to the 0.135 blur ratio observed at $25 \mathrm{~m}$ in the analysis above of the first five motif sounds [Fig. 4(c)].

\section{Excess attenuation}

The ANOVA on the excess attenuation also showed significant main effects for microphone height and sound, where as that of speaker height was not significant (Table VIII). The effects of the two-factor interactions were significant for sound by speaker height and for speaker height by microphone height, but not quite significant for sound by microphone height (Table VIII). Together, the main effects and two-factor interactions explained about $89 \%$ of the variation.

The multiple range analysis for excess attenuation showed the same pattern as for blur ratio, i.e., that excess attenuation was clearly different only for 9 and $3 \mathrm{~m}$ with the latter being greatest [Fig. 11(b)]. Sounds could again

TABLE VIII. ANOVA table for excess attenuation. Details as in Table VII.

\begin{tabular}{lrrc}
\hline \hline Source of variation & d.f. & $F$ ratio & $P$ \\
\hline Main effects & 12 & 5.790 & 0.0005 \\
$\quad$ Speaker height & 1 & 0.230 & 0.6421 \\
Microphone height & 2 & 12.795 & 0.0003 \\
Sound & 9 & 4.851 & 0.0022 \\
Two-factor interactions & 29 & 2.679 & 0.0160 \\
Speaker height by & 2 & 4.309 & 0.0296 \\
$\quad$ microphone height & 9 & 3.602 & 0.0099 \\
Speaker height by sound & 18 & 2.037 & 0.0704 \\
Microphone height by sound & & & \\
\hline \hline
\end{tabular}
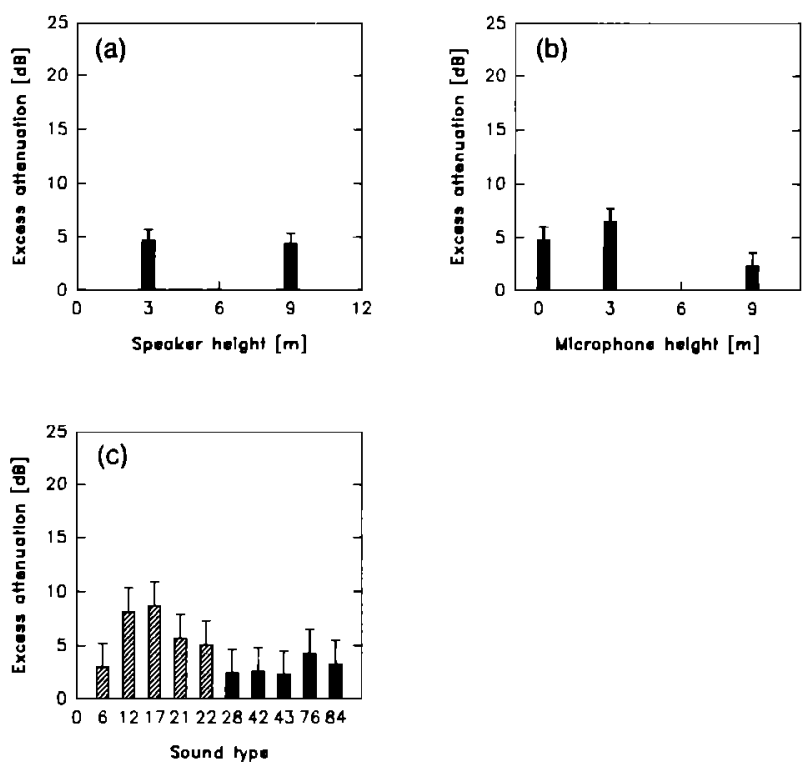

FIG. 11. The degree of excess attenuation of twitter sounds $T-6, T-12$, $\mathrm{T}-17, \mathrm{~T}-21$, and T-22 and motif sounds M-28, M-42, M-43, M-76, and M-84 analyzed in a three-way factorial ANOVA, showing levels of main factor effects. Nomenclature as in Fig. 10.

be divided into two clearly different groups, one consisting of $\mathrm{T}-12$ and $\mathrm{T}-17$ with the highest excess attenuation, and the other of T-6 plus M-28, M-42, M-43, and M-84 with the lowest attenuation [Fig. 11(c)]. Again, if the number of levels for the factor sounds was reduced to two, twitter and motif sounds, then the main effect was still highly significant. The excess attenuation of twitter and motif sounds was clearly different (means of 6.1 and $3.0 \mathrm{~dB}$, respectively). The excess attenuation of $3.0 \mathrm{~dB}$ for motif sounds is close to that of $4.0 \mathrm{~dB}$ observed at $25 \mathrm{~m}$ for the first five motif sounds. Note also that the excess attenuation of $6.1 \mathrm{~dB}$ for twitter sounds at a distance of $25 \mathrm{~m}$ is virtually identical with that of the first five motif sounds at $50 \mathrm{~m}(6.4 \mathrm{~dB})$ [Fig. 6(c)].

The two-factor means among other things showed that the absolutely lowest excess attenuation of $0.9 \mathrm{~dB}$ was found for both microphone and speaker placed $9 \mathrm{~m}$ above ground. All other combinations showed mean excess attenuations varying between 3.8 and $7.5 \mathrm{~dB}$. This pattern, however, strongly depended on the type of sound. For instance, the two-factor means for the five motif sounds were clearly smaller for the microphone height of $9 \mathrm{~m}$ (grand mean: $0.06 \mathrm{~dB}$ ) than for those of 3 and $0.2 \mathrm{~m}$ (grand means: 5.0 and $3.9 \mathrm{~dB}$, respectively). The two-factor means for the twitter sounds did not show the same relatively small excess attenuation at a microphone height of $9 \mathrm{~m}$ (grand means: $5.0 \mathrm{~dB}$ for $9 \mathrm{~m}, 8.0 \mathrm{~dB}$ for $3 \mathrm{~m}$, and $5.6 \mathrm{~dB}$ for 0.2 $\mathrm{m})$. At a speaker height of $3 \mathrm{~m}$ the two types of sound had similar excess attenuations (grand means: $4.8 \mathrm{~dB}$ for motif sounds and $4.6 \mathrm{~dB}$ for twitter sounds), whereas at $9 \mathrm{~m}$, the motif sounds had a clearly lower excess attenuation (grand mean: $1.2 \mathrm{~dB}$ ) than the twitter sounds (grand mean: 7.6 dB). Finally, the mutual ranking of the sounds' excess attenuations within the two types of sound varied with both speaker and microphone height. 
TABLE IX. ANOVA table for signal-to-noise ratio. Details as in Table VII.

\begin{tabular}{lrrr}
\hline \hline Source of variation & d.f. & $\boldsymbol{F}$ ratio & \multicolumn{1}{c}{$\boldsymbol{P}$} \\
\hline Main effects & 12 & 50.559 & $<0.0001$ \\
Speaker height & 1 & 0.939 & 0.3556 \\
Microphone height & 2 & 6.895 & 0.0060 \\
Sound & 9 & 65.776 & $<0.0001$ \\
& 29 & 1.965 & 0.0683 \\
Two-factor interactions & 2 & 4.376 & 0.0283 \\
Speaker height by microphone height & 9 & 2.351 & 0.0587 \\
Speaker height by sound & 18 & 1.504 & 0.1974 \\
Microphone height by sound & & & \\
\hline \hline
\end{tabular}

\section{Signal-to-noise ratio (S/N)}

The ANOVA on the $S / N$ showed the same tendencies as those for the excess attenuation: Main effects were significant for microphone height and sounds, but nonsignificant for speaker height; effects of two-factor interactions were almost significant for sound by speaker height, and significant for speaker height by microphone height, but nonsignificant for sound by microphone height (Table IX). Together, the main effects and the two-factor interactions explained almost $\mathbf{9 7 \%}$ of the variation.

The multiple range analysis showed a clear difference between the heights of 3 and $0.2 \mathrm{~m}$ with the highest value at the latter height [Fig. 12(b)]. A similar analysis revealed four clearly different groups of sounds. M-43 had the highest $S / N$, while successively lower $S / N$ were found in the groups formed by $M-28+M-42, M-76+M-84$, and $T-12$ $+T-22$. T-6, T-17, and T-21 formed a transition between the latter two groups (Fig. 12c). The grand means for twitter and motif sounds, however, were clearly different
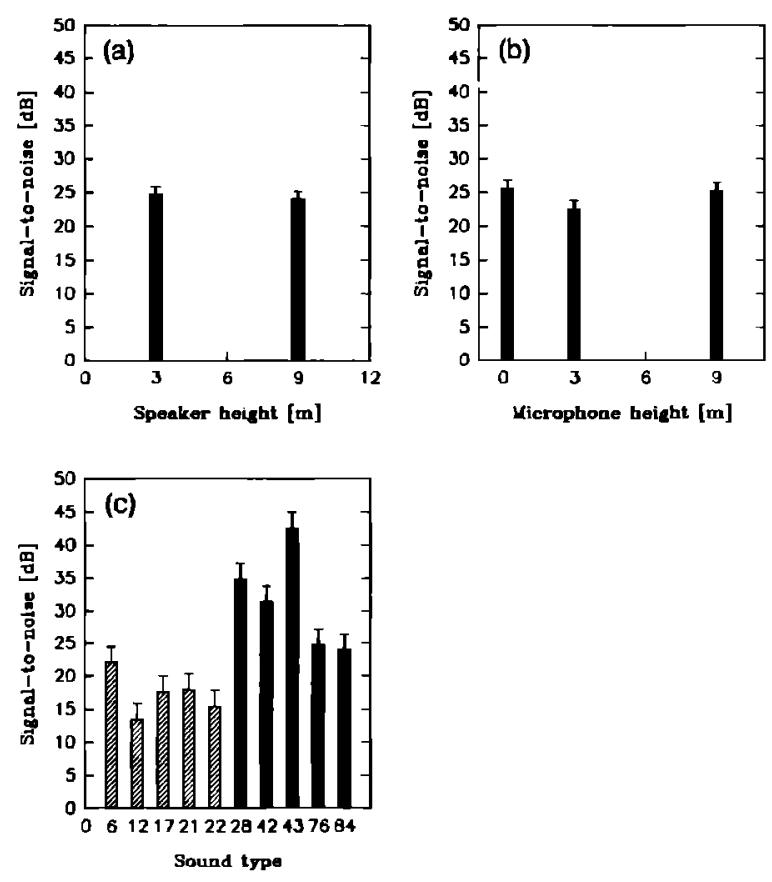

FIG. 12. The signal-to-noise level of twitter sounds T-6, T-12, T-17, T-21, and T-22 and motif sounds $M-28, M-42, M-43, M-76$, and $M-84$ analyzed in a three-way ANOVA, showing levels of main factor effects. Nomenclature as in Fig. 10.
(17.3 and $31.5 \mathrm{~dB}$, respectively). Concordantly, a reduction of the number of levels for the factor sounds to two also here produced a highly significant main effect of sounds $(p<0.0001)$. Note again, the close correspondence between the $S / N$ of $31.5 \mathrm{~dB}$ for the present motif sounds and the $S / N$ of $33.0 \mathrm{~dB}$ for the first five motif sounds at 25 m [Fig. 8(c)].

The two-factor means for $S / N$ showed the highest variation with microphone height at a speaker height of 9 $m$ (between 20.7 and $26.0 \mathrm{~dB}$ ). At this speaker height the $\mathrm{S} / \mathrm{N}$ was clearly lowest at a microphone height of $3 \mathrm{~m}$. Another striking point is that the $\mathrm{S} / \mathrm{N}$ for the five twitter sounds were always the highest at the speaker height of 3 $\mathrm{m}$, while the opposite was true for the five motif sounds.

\section{Correlations}

The three measures of degradation were also mutually correlated for the 60 twitter plus motif sound observations at $p<0.0001$ and the correlation coefficients were also similar, i.e., $r s=-0.62$ between blur ratio and $\mathrm{S} / \mathrm{N}$, $r s$ $=-0.64$ between excess attenuation and $\mathrm{S} / \mathrm{N}$, and $r s$ $=0.68$ between blur ratio and excess attenuation.

\section{DISCUSSION}

\section{A. Degradation as a function of transmission distance}

It has been discussed (Michelsen, 1978) whether excess attenuation is best expressed in $\mathrm{dB} / \mathrm{m}$ (inferring $a b-$ sorption as the main source of attenuation) or in $\mathrm{dB} / \mathrm{dd}$ ( $\mathrm{dB}$ per doubling of distance; multiple scattering is the main source). Our measurements do not allow us immediately to prefer one over the other since linear regression of the excess attenuation values against distance and against log distance produce equal coefficients of determination: $r^{2}=0.433$ and 0.430 , respectively. Expressed in linear terms, the average excess attenuation of the five motif sounds is $0.08 \mathrm{~dB} / \mathrm{m}$. This value is comparable to the findings of Marten and Marler [1977; Fig. 3(c)] estimating an excess attenuation of about $10 \mathrm{~dB} / 100 \mathrm{~m}$ in a deciduous forest without leaves. Extrapolation of the linear attenuation, however, predicts an unrealistic excess attenuation of $2.3 \mathrm{~dB}$ at the source $(0 \mathrm{~m})$. Expressed in logarithmic terms the excess attenuation is $3.9 \mathrm{~dB} / \mathrm{dd}$, and here extrapolation more realistically predicts the effect to start being noticeable at a distance of about $14 \mathrm{~m}$ from the speaker (Fig. 13).

Taking into consideration the close connection between excess attenuation and $\mathrm{S} / \mathrm{N}$, it is not surprising to find by linear regression that for the five motif sounds the overall reduction in $\mathrm{S} / \mathrm{N}$ is $10 \mathrm{~dB} / \mathrm{dd}$ (Fig. 13). The increase in total attenuation $=$ excess attenuation + geometric attenuation $=3.9 \mathrm{~dB} / \mathrm{dd}+6 \mathrm{~dB} / \mathrm{dd}$. One might argue therefore that $S / N$ together with blurring would suffice as a degradation measure. However, for detection to take place the bird needs not only a sufficiently high $S / N$, but also requires the sound pressure of the received sound signal to exceed its hearing threshold. A knowledge of the SPL of the sound signal at the source in addition to that of 

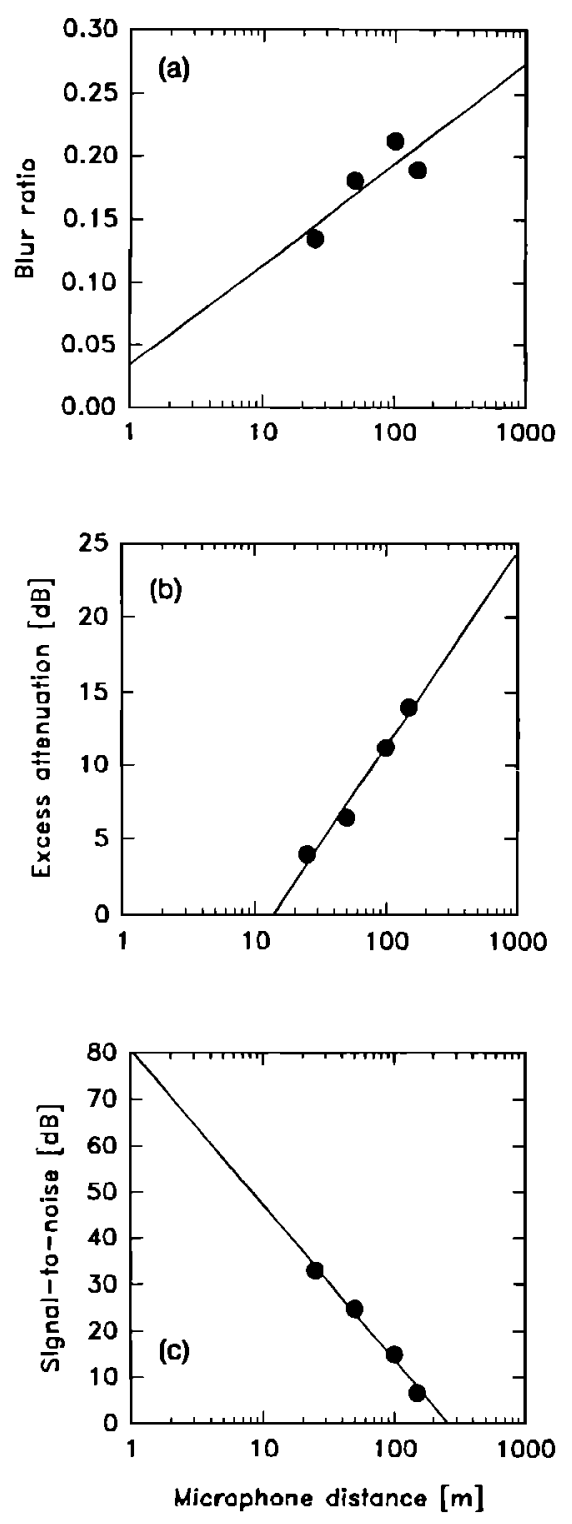

FIG. 13. Degradation of motif part sounds M-2, M-12, M-41, M-56, and M-88 as a function of the horizontal distance from speaker to microphone on a logarithmic scale: (a) blur ratio, (b) excess attenuation, (c) signalto-noise level. Straight lines: linear regression lines. Closed circles: levels of microphone distance effects determined in the four-way ANOVA's of Figs. 4, 6, and 8 .

excess attenuation and $\mathrm{S} / \mathrm{N}$ allow for predictions about detectability at a given position. Data on $\mathrm{S} / \mathrm{N}$ alone would not.

The blur ratio increases up to $100 \mathrm{~m}$, but reduces again at $150 \mathrm{~m}$ (Fig. 4). The reduction at $150 \mathrm{~m}$ may be due to certain local conditions, e.g., a diverging distribution and amount of trees. It indicates that the variation in blurring may be less regular than that of excess attenuation or $\mathrm{S} / \mathrm{N}$. Linear regression on blur ratio versus distance and $\log$ (distance) produce slightly different coefficients of determination, $r^{2}=0.057$ and $r^{2}=0.083$, respectively. Also, extrapolation predicts an unexpected blur ratio of about 0.15 at the source for blur ratio expressed as ratio/m, whereas it is gradually reduced to 0 at the source when expressed logarithmically. These findings suggests that blur ratio might best be described as varying with log distance. The overall increase in blur ratio determined in this way is 0.024 per doubling of distance (Fig. 13). Our measure of blurring is difficult to compare to earlier attempts at quantifying blurring, since it is a direct measure. Earlier studies have used less reliable methods such as ranking of peak values obtained from a graphic level recorder (e.g., General Radio 1523, Gish and Morton, 1981).

\section{B. Relative degradation of different types of song and motif sound}

At a distance of $25 \mathrm{~m}$, the twitter sounds were blurred and excess attenuated about twice as much as the motif sounds, and the $\mathrm{S} / \mathrm{N}$ of the twitter sounds was only about half of that of the motif sounds in spite of the fact that the background noise was considerably lower in their part of the spectrum. The motif sounds must be transmitted between 40 and $170 \mathrm{~m}$ in order to be similarly degraded, and, at a distance of $150 \mathrm{~m}$, the twitter sounds were barely detectable by humans having a hearing threshold 10-20 dB lower than that of oscines in the part of the spectrum of the twitter sounds (e.g., Dooling, 1980; Fay, 1988). The rapid degradation of twitter sounds is consistent with the finding that pure twitter song is usually emitted only when approaching an intended receiver or when the distance to the receiver is relatively small (Dabelsteen, 1985; Dabelsteen and Pedersen, 1988b, 1990). The difference in $\mathrm{S} / \mathrm{N}$ between motif and twitter sounds applies to an emitter facing an intended receiver. When the emitter sits with its side or back to a receiver this difference will be even greater, since the radiation pattern of the high pitched twitter sounds is more directional than lower pitched motif sounds (SPL reduced by more than $6 \mathrm{~dB}$ in the caudal field $\left(90^{\circ}\right.$ to $\left.270^{\circ}\right)$ relative to the SPL in the forward direction $\left(0^{\circ}\right)$; Larsen and Dabelsteen, 1990).

The motif sounds differed in their degradation. All four constant frequency CF figures (M-12, M-43, M-56, M-76) were placed in the two homogeneous groups with the smallest blur ratio (M-12+M-56 and M-28+M-43 +M-76), whereas five of six FM and MIX figures were placed in the two groups with the largest blur ratio (M-2 $+\mathrm{M}-41+\mathrm{M}-88$ and $\mathrm{M}-42+\mathrm{M}-84)$. A variation in excess attenuation was indicated for the five repeated motif sounds which were recorded also at distances longer than $25 \mathrm{~m}$ and hence were most exposed to this factor. Among these, the CF figures scored one with a relatively low excess attenuation and one with a relatively high one, whereas the other two types together scored one with a low and two with a high excess attenuation. The same scores were found with regard to $S / N$. That the CF figures are most resistant to degradation is advantageous because constant frequency sounds must be present if species discrimination is to take place in both males and females, whereas FM and MIX figures are dispensable (Dabelsteen and Pedersen, 1992, 1993). The CF type of sound is also the most frequent sound type in the beginning of the motif part facilitating a quick detection and discrimination. The roles of FM and MIX figures seem to be to convey information about the ensuing behavior or response of the singer (FM 
TABLE X. Change in sound degradation with change in the vertical position of the communicant (main effects). The asterisk indicates that the change is not significant. The values in brackets for motif sound figures M-2, M-12, M-41, M-56, and M-88 indicate the horizontal distance in meters toward $(-)$ or away from $(+)$ the emitter which a receiver located $100 \mathrm{~m}$ away from the emitter must move to get the same average change in degradation as that produced by moving upwards the indicated distance. Note that the values for excess attenuation and $\mathrm{S} / \mathrm{N}$ differs strongly between the two groups of motif sound figures due to the fact that M-28, M-42, M-43, M-76, and M-84 were only measured at the short distance (25 $\mathrm{m}$ ) where the average effect of excess attenuation is relatively low.

\begin{tabular}{|c|c|c|c|}
\hline \multirow[b]{2}{*}{ Degradation type } & \multicolumn{3}{|c|}{ Change in vertical position (m) } \\
\hline & $0.2 \rightarrow 3$ & $0.2 \rightarrow 9$ & $3 \rightarrow 9$ \\
\hline $\begin{array}{l}\text { Receiver } \\
\text { M-2, M-12, M-41 } \\
\text { M-56, M-88 }\end{array}$ & & & \\
\hline $\begin{array}{l}\text { Blur ratio } \\
\text { Excess att. (dB) } \\
S / N(d B)\end{array}$ & $\begin{array}{c}+0.03(+152 \mathrm{~m}) \\
-1.2(-5 \mathrm{~m}) \\
-1.1(+8 \mathrm{~m})\end{array}$ & $\begin{array}{l}-0.05(-74 \mathrm{~m}) \\
-6.2(-36 \mathrm{~m}) \\
+2.9(-18 \mathrm{~m})\end{array}$ & $\begin{array}{l}-0.08(-89 \mathrm{~m}) \\
-5.0(-29 \mathrm{~m}) \\
+4.0(-24 \mathrm{~m})\end{array}$ \\
\hline $\begin{array}{l}\text { M-28, M-42, M-43 } \\
\text { M-76, M-84 }\end{array}$ & & & \\
\hline $\begin{array}{l}\text { Blur ratio } \\
\text { Excess att. (dB) } \\
S / N \text { (dB) }\end{array}$ & $\begin{array}{l}+0.03 \\
+1.1 \\
-2.6\end{array}$ & $\begin{array}{l}-0.08 \\
-1.5 \\
-1.3\end{array}$ & $\begin{array}{l}-0.1 \\
-2.6 \\
+1.3\end{array}$ \\
\hline $\begin{array}{l}\text { T-6, T-12, T-17 } \\
\text { T-21, T-22 }\end{array}$ & & & \\
\hline $\begin{array}{l}\text { Blur ratio } \\
\text { Excess att. (dB) } \\
\text { S/N (dB) }\end{array}$ & $\begin{array}{l}+0.02 \\
+2.4 \\
-3.5\end{array}$ & $\begin{array}{l}-0.02 \\
-0.9 \\
+0.5\end{array}$ & $\begin{array}{l}-0.04 \\
-3.3 \\
+4.0\end{array}$ \\
\hline $\begin{array}{l}\text { Emitter } \\
\text { M-2, M-12, M-41 } \\
\text { M-56, M-88 } \\
\text { Blur ratio } \\
\text { Excess att. (dB) } \\
\text { S/N (dB) }\end{array}$ & & & $\begin{array}{l}-0.001^{*} \\
-1.8 \\
+1.5\end{array}$ \\
\hline
\end{tabular}

figures) and to add to the possibilities of communicating individual identity (MIX figures) (Dabelsteen and Pedersen, 1992).

The above considerations are based on main effect means of the three measures of degradation. The raw data together with the two-factor interaction means, however, show a considerable variation regarding which motif sound is the most/least degraded at the different combinations of speaker and microphone position. The sound that is most blurred at a certain combination is not necessarily the one which is excessively attenuated and the one that has its $\mathrm{S} / \mathrm{N}$ most reduced. This implies two things: First, the species characteristic patterns with which the sounds' duration and amplitude vary across the motif part must be difficult to maintain after transmission through the habitat. Accordingly, both of these patterns were found to be unnecessary for species discrimination in both males and females (Dabelsteen and Pedersen, 1992, 1993). Second, in spite of the fact that the blackbird is immobile during full singing, a certain number of each of the three types of motif sounds is likely to reach a receiver relatively undegraded, hence preserving a possibility of attracting its attention. Actually, this consequence may be one of the factors accounting for the evolution of the great intraindividual variation in blackbird motif sounds allowing continuous sound type switching. Having first detected and/or discriminated a singer, a receiver can always change its position in order to improve its possibilities of reading the song (see below).

A possible alternative to the blackbird's strategy of combining immobility with continuous switching between a great number of very different sounds may be to combine bout emittance of sounds from a small repertoire with frequent shifts of position during singing as in the great tit, Parus major (e.g., Gompertz, 1961). This alternative strategy may also ensure that some sounds reach a receiver relatively undegraded because the sounds may be influenced differently by being transmitted to a receiver from slightly different angles and hence through different paths within short time.

\section{Degradation and relative vertical positions in the habitat}

In general, listening blackbirds may reduce degradation of motif sounds substantially by simply avoiding the undergrowth zone 0.5 to $5 \mathrm{~m}$ above the ground (Table $\mathrm{X}$ ), despite the increased level of the background noise above the undergrowth. Similar improvements in transmission may be obtained by moving closer to the singer, but the distances required are large. A territory owner that moves from 3 to $9 \mathrm{~m}$ above the ground in order to reduce blurring and hence to increase the readability of a rival's song would have to approach the rival horizontally by $89 \mathrm{~m}$ (Table X). Accordingly, territory owners usually respond 
to weak rival motif song initially by moving upwards in the vegetation. On the other hand, if they detect pure twitter song they usually go directly toward the source, probably for two reasons: First, there is little advantage in moving up in the vegetation since this will cause a smaller reduction in degradation of twitter sounds than of motif sounds (Table X). Second, detection of pure twitter song usually means that a rival is in the immediate neighborhood and is therefore a threat, either to the territory owner himself or his mate (Dabelsteen, 1985; Dabelsteen and Pedersen, 1988b).

An emitter seems to obtain a very small decrease in degradation by moving upwards in the vegetation from 3 to $9 \mathrm{~m}$ above the ground. The decrease obtained by moving the speaker from 3 to $9 \mathrm{~m}$ above the ground was not significant for any of the three degradation measures on the five motif and twitter figures measured only at a distance of $25 \mathrm{~m}$. For the five motif sound figures measured also at lang distances, however, there was a small improvement in both excess attenuation and $\mathrm{S} / \mathrm{N}$, by -1.8 , and $1.5 \mathrm{~dB}$, respectively.

Previous studies have suggested that birds sing from specific heights above the ground level in order to maximize or optimize the transmission range of their songs (Lemon et al, 1981). The present study suggests that a blackbird climbs upwards in a habitat like the present one to improve its ability to hear responses to its songs, and not to maximize or optimize the transmission range of its songs. This fits in with the findings that blackbird males often stay in the undergrowth while singing close to a mate engaged in nesting activities, and that they move upwards in situations when it may be important to hear the details of vocal replies and/or challenges, e.g., during advertising song or song duels (e.g., Snow, 1958; personal observations). Also, the high variation of blur ratio with distance at a microphone height of $9 \mathrm{~m}$ (cf. Fig. 5) shows that a receiver may range a sender most accurately from a high position.

An interesting consequence of the difference in sound degradation between receivers positioned in and above the undergrowth is that forest-living blackbird females, on average, must experience a larger degree of song degradation than males. Females usually hide in the undergrowth, whereas males often hear song in relatively open conditions, for example when patrolling territorial borders or when advertizing or duelling. This difference in usual transmission path between males and females is reflected in a difference in sensitivity to song parameters known to be affected by degradation. Females seem to rely less on the upper frequency bands to discriminate species. Females seem to disregard the degree of amplitude modulation of the CF sounds and also the duration of the intersound figure pauses when assessing the behavior of the singer (Dabelsteen and Pedersen, 1988a, 1993). These three parameters degrade more in transmission to females. The negative impact of dense vegetation on the part of the spectrum that includes the upper frequency limit of the blackbird motif part ( $3-4 \mathrm{kHz})$ is well known, as are the echoes caused by vegetation that shorten the intersound pauses
(Wiley and Richards, 1978, 1982; Michelsen, 1978; Richards and Wiley, 1980; Michelsen and Larsen, 1983; this study). The present study shows that the amplitude functions of motif parts are $33 \%-57 \%$ more blurred when received $0.2-3 \mathrm{~m}$ above the ground (by females or males) than when received $9 \mathrm{~m}$ above the ground (usually by a male) [cf. Fig. 4(b)].

\section{Detection and recognition range of blackbird motif parts}

Brenowitz (1982) stated that in order to calculate the communication range of a singing bird one needs information on SPL of the songs at the source, on attenuation as a function of distance, on level of ambient noise, and on masked auditory threshold of the receivers. This ignores blurring. A song may be detectable, but not discriminable. So, Brenowitz's method may overestimate the effective communication range.

It should be possible to estimate the maximal detection range of blackbird motif sounds assuming that the auditory threshold of the blackbird is similar to that of songbirds with vocalizations in the same frequency range. At $2 \mathrm{kHz}$, Passerine auditory thresholds seem to be about $10 \mathrm{~dB}$ SPL (Dooling, 1982; Fay, 1988). At a distance of $14 \mathrm{~m}$, where the excess attenuation starts to be noticeable, the SPL of the motif parts is 57-62 dB(A) (Dabelsteen, 1981). Since the attenuation of the motif sounds was found to be 6 $\mathrm{dB} / \mathrm{dd}$ plus an excess attenuation of $3.9 \mathrm{~dB} / \mathrm{dd}$, detection threshold in the absence of ambient noise should be reached at a distance from the emitter of about $450 \mathrm{~m}$ (Fig. 13).

The redwinged blackbird (Agelaius phoeniceus) seems to require a $\mathrm{S} / \mathrm{N}$ of about $3 \mathrm{~dB}$ to discriminate conspecific song (Brenowitz, 1982). In the present study, this $S / N$ is reached on average at $230 \mathrm{~m}$ for blackbird motif parts, while a $\mathrm{S} / \mathrm{N}$ of $0 \mathrm{~dB}$ occurs at $260 \mathrm{~m}$ (Fig. 13). Therefore, if the European blackbird requires a similar $\mathrm{S} / \mathrm{N}$ as the redwinged blackbird, it should be able to discriminate song at distances up to about $250 \mathrm{~m}$. But again, this estimation of communication range does not consider the consequence of blurring (blur ratio about $0.22-0.23$ at this distance; Fig. 13). In the present habitat, territory diameters range from about 30 to more than $100 \mathrm{~m}$. So, a discrimination distance of about $250 \mathrm{~m}$ ensures that the motif parts will propagate completely across the emitter's own territory and remain effective across the nearest neighboring territories, regardless of the singer's horizontal position in his own territory. This is in accordance with the findings of Brenowitz (1982) for the redwinged blackbird.

\section{ACKNOWLEDGMENTS}

We are grateful to Robert J. Dooling, Georg M. Klump, Stuart G. Martin, Peter K. McGregor, Axel Michelsen, Lee A. Miller, R. Haven Wiley, and an anonymous referee for their valuable comments on a previous draft of this paper. The study was supported by a fellowship from the Carlsberg Foundation (TD) which also funded the 
purchase of the DSP 5500 sonagraph (TD), and by the Danish Natural Science Research Council (ONL, 117765).

Brenowitz, E. A. (1982). "The active space of red-winged blackbird song," J. Comp. Physiol. A 147, 511-522.

Chappuis, C. (1971). "Un example de l'influence du milieu sur les emissions vocales des oiseaux: L'evolution des chants en foret equatoriale," Terre Vie 2, 183-202.

Cosens, S. E., and Falls, J. B. (1984). "A comparison of sound propagation and song frequency in temperate marsh and grassland habitats," Behav. Ecol. Sociobiol. 15, 161-170.

Dabelsteen, T. (1981). "The sound pressure level in the dawn song of the blackbird (Turdus merula) and a method for adjusting the level in experimental song to the level in natural song," $Z$. Tierpsychol. 56, 137-149.

Dabelsteen, T. (1984). "An analysis of the full song of the blackbird Turdus merula with respect to message coding and adaptations for acoustic communication," Ornis Scand. 15, 227-239.

Dabelsteen, T. (1985). "Messages and meanings of bird song with special reference to the blackbird (Turdus merula) and some methodology problems," Biol. Skr. Dan. Vid. Selsk. 25, 173-208.

Dabelsteen, T., and Pedersen, S. B. (1985a). "Correspondence between messages in the full song of the blackbird Turdus merula and meanings to territorial males, as inferred from responses to computerized modifications of natural song," Z. Tierpsychol. 69, 149-165.

Dabelsteen, T., and Pedersen, S. B. (1985b). "A method for computerized modification of certain natural animal sounds for communication study purposes," Biol. Cybern. 52, 399-404.

Dabelsteen, T., and Pedersen, S. B. (1988a). "Do female blackbirds, Turdus merula, decode song in the same way as males?," Anim. Behav. 36, $1858-1860$.

Dabelsteen, T., and Pedersen, S. B. (1988b). "Song parts adapted to function both at long and short ranges may communicate information about the species to female blackbirds Turdus merula," Ornis Scand. 19, 195-198.

Dabelsteen, T., and Pedersen, S. B. (1990). "Song and information about aggressive responses of blackbirds, Turdus merula: evidence from interactive playback experiments with territory owners," Anim. Behav. 40, 1158-1168.

Dabelsteen, T., and Pedersen, S. B. (1992). "Song features essential for species discrimination and behaviour assessment by male blackbirds (Turdus merula)," Behaviour 121, 259-287.

Dabelsteen, T., and Pedersen, S. B. (1993). "Song-based species discrimination and behavior assessment by fernale blackbirds (Turdus merula)," Anim. Behav. 45.

Dooling, R. J. (1980). "Behavior and psychophysics of hearing in birds," in Comparative Studies on Hearing in Vertebrates, edited by A. N. Popper and R. R. Fay (Springer-Verlag, Berlin), pp. 261-288.

Dooling, R. J. (1982). "Auditory perception in birds," in Acoustic Communication in Birds, Vol. I, edited by D. E. Kroodsma and E. H. Miller (Academic, New York), pp. 95-130.

Fay, R. R. (1988). Hearing in Vertebrates: A Psychophysics Databook (Hill-Fay, Winnetka, IL).

Gish, S. L., and Morton, E. S. (1981). "Structural adaptations to local habitat acoustics in Carolina wren songs," $Z$. Tierpsychol. 56, 74-84.

Gompertz, T. (1961). "The vocabulary of the great tit," Brit. Birds 54, 369-394, 409-418.

Kinsler, L. E., and Frey, A. R. (1962). Fundamentals of Acoustics (Wiley, New York).

Klump, G. M., and Maier, E. H. (1989). "Gap detection in the starling (Sturnus vulgaris)," J. Comp. Physiol. A 164, 531-538.
Larsen, O. N., and Dabelsteen, T. (1990). "Directionality of blackbird vocalization. Implications for vocal communication and its further study," Ornis Scand. 21, 37-45.

Lemon, R. E., Struger, J., Lechowicz, M. J., and Norman, R. F. (1981). "Song features and singing heights of American warblers: Maximization or optimization of distance?," J. Acoust. Soc. Am. 69, 1169-1176.

Marten, K., and Marler, P. (1977). "Sound transmission and its significance for animal vocalization. I. Ternperate habitats," Behav. Ecol. Sociobiol. 2, 271-290.

Marten, K., Quine, D., and Marler, P. (1977). "Sound transmission and its significance for animal vocalization. II. Tropical forest habitats," Behav. Ecol. Sociobiol. 2, 291-302.

McGregor, P. K. (1991). "The singer and the song: on the receiving end of bird song," Biol. Rev. 66, 58-85.

McGregor, P. K., and Falls, J. B. (1984). "The response of western meadowlarks (Sturnella neglecta) to the playback of undegraded and degraded songs," Can. J. Zool. 62, 2125-2128.

McGregor, P. K., and Krebs, J. R. (1984). "Sound degradation as a distance cue in the great tit (Parus major) song," Behav. Ecol. Sociobiol. 16, 49-56.

McGregor, P. K., Krebs, J. R., and Ratcliffe, L. M. (1983). "The reaction of great tits (Parus major) to playback of degraded and undegraded songs: the effect of familiarity with the stimulus song type," Auk 100, 898-906.

Michelsen, A. (1978). "Sound reception in different environments," in Sensory Ecology, edited by M. A. Ali (Plenum, New York), pp. 345373.

Michelsen, A., and Larsen, O. N. (1983). "Strategies for acoustic communication in complex environments," in Neuroethology and Behavioural Physiology. Roots and growing points, edited by F. Huber and $\mathrm{H}$. Markl (Springer, Berlin, Heidelberg, New York, Tokyo), pp. 321-331.

Morton, E. S. (1975). "Ecological sources of selection on avian sounds," Am. Natur. 109, 17-34.

Morton, E. S. (1982). "Grading, discreteness, redundancy, and motivation-structural rules," in Acoustic Communication in Birds, Vol. 1, edited by D. E. Kroodsma and E. H. Miller (Academic, New York), pp. 183-212.

Pedersen, S. B., Dabelsteen, T., and Larsen, O. N. (in preparation). “A digital technique for noise-compensated quantification of the degradation of transmitted sound signals."

Price, M. A. (1988). "Sound attenuation through trees: Measurements and models," J. Acoust. Soc. Am. 84, 1836-1844.

Richards, D. G. (1981). "Estimation of distance of singing conspecifics by the Carolina wren," Auk 98, 127-133.

Richards, D. G., and Wiley, R. H. (1980). "Reverberations and amplitude fluctuations in the propagation of sound in a forest: implications for animal communication," Am. Nat. 115, 381-399.

Shy, E., and Morton, E. S. (1986). "Adaptation of amplitude structure of songs to propagation in field habitat in song sparrows," Ethology 72, $177-184$.

Snow, D. W. (1958). A Study of Blackbirds (Allen and Unwin, London). Stephan, B. (1985). Die Amsel Turdus merula (Ziemsen, Wittenberg Lutherstadt), Die Neue Brehrn-Bücherei, Vol. 95.

Waide, R. B., and Narins, P. M. (1988). "Tropical forest bird counts and the effect of sound attenuation," Auk 105, 296-302.

Waser, P. M., and Brown, C. H. (1984). "Is there a 'sound window' for primate communication?," Behav. Ecol. Sociobiol. 15, 73-76.

Wiley, R. H., and Richards, D. G. (1978). "Physical constraints on acoustic communication in the atmosphere: implications for the evolution of animal vocalizations," Behav. Ecol. Sociobiol. 3, 69-94.

Wiley, R. H., and Richards, D. G. (1982). "Adaptations for acoustic communication in birds: transmission and signal detection," in Acoustic Communication in birds, Vol. I, edited by D. E. Kroodsma and E. H. Miller (Academic, New York), pp. 131-181. 